\title{
PAmpa, espaÇo transfronteiriço: Ensaio de GEOPOÉTICA MERIDIONAL
}

\author{
Pampa as border area: an essay on Southern \\ geopoetics
}

\author{
Anselmo Peres Alós* \\ Andrea Cristiane Kahmann**
}

\begin{abstract}
RESUMO
Este artigo propõe a discussão de alguns aspectos históricos relacionados à construção do pampa como um espaço poético. Neste sentido, obras literárias e ensaios históricos são comparados, estudados e analisados no que diz respeito a suas contribuições para a descrição de uma "geopoética meridional" no contexto da América do Sul.
\end{abstract}

Palavras-chave: pampa; fronteiras; América do Sul; geopoética meridional.

\begin{abstract}
This article aims at discussing some historical aspects of the symbolic construction of the pampa as a poetic space. In this sense, literary works and historic papers are compared, studied and analyzed when it comes to their contributions for the description of a "meridional geopoetics" in the context of South America.
\end{abstract}

Keywords: pampa; boundaries; South America; meridional geopoetics.

* Universidade Federal de Santa Maria (UFSM).

** Doutoranda em Literatura Comparada - PPG-Letras/UFRGS. 
o questionamento das tradições na esfera latino-americana teve uma peculiar trajetória no sentido de reavaliar as marcas de pertencimento, posto que as teorias europeias sobre nacionalidade pareciam não dar conta do peculiar fenômeno de consolidação do Estado-nação tipicamente "crioulo". Aos movimentos pela independência político-administrativa, que tiveram lugar no século XIX, seguiram-se as tentativas de rupturas com um passado comum colonizador e de preenchimento dos vazios deixados pela consciência coletiva amparada em tradições alheias e ilegítimas. Tendo em vista que o latino-americano compóe o Outro do europeu, cabia definir quem seria o Outro do latino-americano ${ }^{1}$. Na formação de sua identidade, restava cunhar a alteridade e delimitar suas fronteiras. Um paradoxo evidente: o nacionalismo incipiente da América Latina era "culturalmente colonial e politicamente anticolonial" (OLIVEIRA, 2004, p. 53). O caso do gaúcho transplatino foi ainda mais interessante: não se encaixando na sociedade do branco europeizado, nem na do índio, ele vacilou no entrelugar ${ }^{2}$ das conformações identitárias mas, após a demarcação das fronteiras e o cercamento dos campos, assumiu novos contornos de significação para os promotores dos discursos nacionalistas. Em um evidente processo de civilização da barbárie, a imagem do gaúcho restou acomodada como símbolo inventado por uma comunidade ansiosa por engessar as fraturas culturais.

De certa forma homogêneo no plano cultural, o "gaúcho", politicamente falando, foi a consequência de uma zona de conflitos entre três soberanias. De acordo com Leenhardt, "houve três quando Espanha e Portugal se uniram contra as reduções jesuíticas, houve três depois que o Uruguai se tornou um Estado, do mesmo modo que houve três quando foi o Paraguai que se tornou em objeto de cobiça" (LEENHARDT, 2002, p. 27). Não obstante, a história de lutas entre os atores platinos esfacela-se ante a constatação de como "modos de vida e culturas se constroem ou sobrevivem apesar dos recortes que os atravessam, e constituem, à sua maneira, um espaço diferente daquele que tentam definir os Estados, um Estado de cultura mais do que de dispositivos estatais de proteção" (LEENHARDT, 2002, p. 29). No contexto pampiano, fronteiras culturais e linguagem resistem às delimitações geopolíticas bem mais do que o estabelecido em tratados; mesclam-se, em suas trilhas, ambivalências e ambiguidades de ordem social, linguística, e mesmo existencial. Nesse pampa uno e indivisível, que antecipava os trata-

1 Afinal, recorda-se, com Cottet, o tema lacaniano da crítica da intersubjetividade: "não se deduz o sujeito de outro sujeito, mas o sujeito é suposto pelo significante que o representa junto a um Outro" (COTTET, 1989, p. 20).

2 A expressão é aqui tomada no sentido dado por Silviano Santiago no ensaio que abre seu Uma literatura nos trópicos (2000), e não no sentido atribuído ao pensamento pós-colonial de Homi K. Bhabha em seu O lugar da cultura (1998). 
dos políticos de integração, era mister que a literatura assumisse contornos mais afeitos a essa nova relação entre localismo americano e universalismo europeu. Alguns críticos - pode-se pensar aqui em Wander Miranda, Beatriz Sarlo e Silviano Santiago - chegaram a pensar na literatura latino-americana como "la quintaesencia de la posmodernidad y la diferencia" (CAMPA, 1996, p. 698). E a literatura pampiana, por sua vez, não fica para trás: acompanha as idas e vindas entre brasileiros e uruguaios, construindo e questionando mitos para, enfim, consagrar o interstício, o limiar e o espaço intervalar com todas as suas cargas de integração, com suas zonas de contato ${ }^{3}$ e com seus influxos platinos.

\section{IdAs E VINDAS ENTRE Brasil e URUguai}

Para compreender as questões que envolvem a literatura que subverte as fronteiras políticas no entorno pampiano, é necessário atentar aos eventos históricos que influenciaram a constituição dos sistemas simbólicos de referência dos três Estados que convivem nesse espaço transfronteiriço. Cabe recordar que, até a criação do Vice-Reinado do Rio da Prata, em 1776, as principais atividades da economia rioplatense foram, simultaneamente, a exportação legal de couro e de charque e o contrabando de prata, mercadorias e escravos. Esse papel, um pouco esquizofrênico dentro da economia colonial (em que o comércio legal e o ilegal conviviam de forma intensa), permitiu a formação de uma próspera rede de contrabando organizado, da qual participavam comerciantes, funcionários da burocracia civil, militar e eclesiástica e, inclusive, governadores (BEIRED, 1996, p. 9-21). Após o episódio do Domínio Espanhol e da perda de importantes territórios no Oriente e na África, além da presença holandesa cravada no nordeste brasileiro, a região do Prata, espanhola por convenção, passou a despertar o interesse dos portugueses. A ideia era recolher a prata de Potosí e oferecer, em troca, artigos coloniais, como açúcar e mão-de-obra africana escravizada, bem como produtos manufaturados ingleses. Os britânicos, afoitos por novos mercados, incentivaram as ambições lusitanas.

Dessa forma, em 1680, os portugueses fundaram a Colônia do Sacramento na margem esquerda do Rio da Prata, rente à cidade de Buenos Aires. A resposta a tão ousado evento não tardou: em 1726, os espanhóis fundaram o forte de San Felipe, denominado, mais tarde, Montevideo, também na margem esquerda do Prata, isolando a comunicação com o território português ao norte (PESAVENTO, 2002, p. 10-12). Após sucessivos episódios

3 Articula-se aqui a categoria no sentido desenvolvido por Mary Louise Pratt (1991). 
de conquista e retomada de territórios, as disputas envolvendo a Colônia do Sacramento e o entorno das Missões motivou inúmeros acordos entre as Coroas Ibéricas, entre eles o Tratado de Madrid, em 1750, com seu famigerado desfecho da "Guerra Guaranítica" (1754-1756). Contudo, a expulsão dos portugueses da Colônia de Sacramento só ocorreu em 1777, quando os espanhóis já ocupavam dois terços do território que constitui, hoje, o Uruguai. Por outro lado, a reconquista das Missões Orientais pelos portugueses teve lugar em 1801, ocasião em que o Rio Grande do Sul conquistou sua fronteira oeste (PESAVENTO, 2002, p. 23).

Em 1811, três anos após a chegada da Corte portuguesa à Bahia, ocorreu a primeira tentativa de independência uruguaia, sob a liderança de José Gervasio Artigas. Proclamada a independência de Espanha e a organização de um Estado confederado, Artigas decretou, em 1815, a repartição das terras, ocupadas em sua totalidade pelos inimigos da revolução: ademais dos espanhóis, uma aristocracia agrária crioula comprometida com a Coroa. O Reglamento de 1815 previa a divisão das terras entre los más infelices: índios, negros livres (os que haviam aderido à Revolução) e criollos pobres. Conforme Romano, a literatura desempenhou um importante papel nesse contexto revolucionário. Ao brotarem as primeiras publicações populares de poesias, as ideias artiguistas acabaram por integrar regiões e setores sociais diversos, tumultuando as negociações com Buenos Aires. O receio de que tais ideias encontrassem terreno fértil no Brasil, infestando o Estado brasileiro pela fronteira do Rio Grande do Sul, fez com que Carlota Joaquina enviasse, do Rio de Janeiro, uma imprensa com a qual se editaria a Gaceta de Montevideo, para respaldar a postura antirrevolucionária (ROMANO, 1994, p. 131). A velha classe alta do período colonial acabou, assim, por aliar-se aos invasores portugueses. Importante destacar que foram dois os motivos principais da invasão portuguesa ao Uruguai: ocupar um território em disputa com a Espanha desde longa data e evitar que o Sul do Império, especialmente o Rio Grande do Sul, aderisse às ideias republicanas e federativas de Artigas. De 1816 a 1820, os apoiadores de Artigas resistiram à invasão lusa, mas o Uruguai acabou sendo anexado ao Império Português e, com a independência do Brasil, em 1822, recebeu o nome de Província Cisplatina.

Os habitantes da banda oriental, em um primeiro momento, aceitaram a presença do invasor, que prometia a ordem e a devolução das terras confiscadas por Artigas. No entanto, aos poucos, foram percebendo que os lusitanos eram preferidos no reparto das terras e das concessões comerciais. Em 1825, teve lugar a segunda etapa da Revolução, quando os 33 orientales, encabeçados por Juan A. Lavalleja, declararam guerra ao Brasil, apoiados por uma Buenos Aires ansiosa por reincorporar o território uruguaio. No entanto, o "Estado Oriental do Uruguai", definido pela Constituição de 1830, teve sua independência muito mais influenciada pelo comércio britânico do que pelas armas. 
O conflito com o a Banda Oriental tinha mobilizado uma intensa campanha militar no Rio Grande do Sul, que durou até 1828. A perda da Cisplatina representou a perda do gado uruguaio para os saladeros platinos que se rearticulavam em detrimento das charqueadas sul-rio-grandenses, $o$ que acentuou a insatisfação da oligarquia sulina. Além disso, os gaúchos compartilhavam com os vizinhos castelhanos anseios separatistas e federalistas, de modo que tomaram o exemplo dos uruguaios e fizeram eclodir a Revolução Farroupilha (1835-1845). Há que se notar que foi em função das fortes ligações com o Prata que os promotores do levante farroupilha puderam sustentar dez anos de guerra contra o Império ${ }^{4}$. Da mesma forma, foi somente em vista da iminência de novos conflitos no Prata que o Império, necessitado do apoio gaúcho, ofereceu uma paz ${ }^{5}$, em que ficou evidente "o poder militar do Rio Grande do Sul como elemento de barganha frente ao poder central" (PESAVENTO, 2002, p. 40).

Especialmente nos departamientos do Norte e do Leste uruguaios, os brasileiros eram dominantes. Dessa forma, já em 1888, Itaqui, Quaraí e Uruguaiana estavam ligadas a Montevideo e Salto pela via férrea. Em contraste, só em 1907 é que os trilhos da ferrovia gaúcha estabeleceram conexão com Porto Alegre (FRANCO, 1992, p. 34). Esse "isolamento" da fronteira brasileira com relação ao próprio Brasil fez com que, até meados de 1920, boa parte da produção do Oeste gaúcho fosse escoada através do porto de Montevideo que, ademais da proximidade e boa infraestrutura, cultivava um sistema de baixas tarifas de importação. As elites vinculadas ao setor agropastoril no Rio Grande do Sul atacavam com veemência os efeitos da participação uruguaia no comércio gaúcho. Borges de Medeiros, mais de uma vez, enfatizou em suas mensagens a necessidade de livrar o Rio Grande da influência platina (DIAS, 1998, p. 151). Questões comerciais, econômicas, políticas ou sociais eram resgatadas para insuflar o ódio da população contra o Outro - tanto de um quanto de outro lado da fronteira.

Nessa linha, pode-se afirmar que também o pampa foi inserido, conforme perspectiva sociológica sugerida por Souza Martins, em uma situação de fronteira "como lugar social de alteridade, confronto e conflito" (MARTINS, 1997, p. 36). Os sucessivos episódios de guerra, intervenção e exploração econômica a que o Brasil subjugou o vizinho Uruguai fazem

4 Sandra J. Pesavento recorda que, durante todo o período da Revolução, a barra do Rio Grande permaneceu fechada aos farrapos, pois esta cidade estava em mãos dos "legalistas" (PESAVENTO, 2002, p. 39).

5 A propósito, "os farrapos conseguiram elevação de $25 \%$ da taxa alfandegária sobre o charque importado e o direito dos estancieiros escolherem naquele momento o seu presidente de província (foi escolhido o próprio Caxias). Por outro lado, ficou acertado que as dívidas contraídas seriam pagas pelo governo central, e que todos os farrapos poderiam passar para o exército brasileiro com os mesmos postos com que lutavam nas forças rebeldes" (PESAVENTO, 2002, p. 40). 
retomar a afirmação de que "certamente, o caso da frente de expansão brasileira, como provavelmente o caso de outros países, não corresponde à idílica suposição de que a fronteira é o lugar de concepções e práticas democráticas de autogestão e liberdade" (MARTINS, 1997, p. 39). Souza Martins opõe-se a outros sociólogos que encaram a fronteira como comemoração do diálogo e do pluralismo, uma vez que "é fora de dúvida que a fronteira é um lugar de morte” (MARTINS, 1997, p. 37). Morte não só nas guerras pelo território, mas também uma morte simbólica, cultural e social, promovida pela apropriação e degradação do outro, já que "nesse sentido, a fronteira tem um caráter litúrgico e sacrificial, porque nela o outro é degradado para, desse modo, viabilizar a existência de quem o domina, subjuga, explora" (MARTINS, 1997, p. 13).

Interesses políticos buscavam soterrar a unidade da Campanha. Assim, promoveu-se entre o habitante desses pagos o encargo de viver com o inimigo. Porém, sobre o estancieiro-soldado do entorno pampiano, pairava a incerteza de saber quem seria esse inimigo e qual seria a última fronteira, a depender do desfecho das guerras e das tratativas diplomáticas. E há que se notar que, para o gaúcho do Rio Grande do Sul de então, a ideia de pertencer a uma unidade colonial com regência no Rio de Janeiro trazia o sério problema de se sentir deslocado de seu horizonte imediato. A afirmação do povo rio-grandense forjou-se, portanto, em face do poder central brasileiro e da proximidade ora ameaçadora, ora atraente das terras castelhanas. Reverbel observa que "a fronteira do Rio Grande [do Sul] com os países do Prata estende-se por 1.727 quilômetros. [...] A fronteira com o Uruguai, desde a barra do Chuí até a foz do Quaraí, é quase toda seca. [...] Nada, entretanto, impede o livre trânsito entre o Rio Grande e os países platinos" (REVERBEL, 1998, p. 89).

A inexistência de obstáculos naturais para a transposição da fronteira geográfica, especialmente se considerada a uruguaia, permitiu o livre trânsito de pessoas, contrabando, gado e ideias. O (auto)reconhecimento do gaúcho conformou-se a partir de um vínculo com o lugar, muito mais do que com o espaço ${ }^{6}$, , constituindo uma identidade precária, desvinculada das noções de país, pátria ou nacionalidade. A propósito, Guilhermino César aponta que, no pampa de fronteira aberta, os limites moldavam-se de acordo com a nacionalidade do possuidor das terras e que a língua era o principal fator de reconhecimento:

6 Lugar deve ser entendido como o ponto de práticas sociais específicas, concreto e delimitado pelo contexto com o qual as identidades estão estreitamente vinculadas (HALL, 2003, p. 70-76). 
Nenhuma das duas Coroas [...] saberia dizer a seus vassalos por onde passavam, no terreno, as respectivas linhas confrontantes. A posse das coisas, portanto, não se dava em um espaço nacional conhecido. O possuidor, com a sua nacionalidade, é que delimitava, por assim dizer, a soberania do seu Estado. Onde se achava um súdito espanhol, o território era espanhol; e vice-versa com respeito ao português. Ambos usufruíam, segundo seu alvedrio, a "terra-de-ninguém" [...].

Todavia, para os crioulos, isto é, os nativos da "terra de ninguém", a questão da nacionalidade complicava-se bastante. Quem lhes marcava a cidadania era o idioma; no anonimato em que viviam, diante da civilização, a fala materna fazia as vezes de certidão de idade. Até onde chegava, por conseguinte, a jurisdição de fato daqueles enclaves - Colônia do Santíssimo Sacramento, Rio Grande de São Pedro, Siete Pueblos da margem esquerda do Rio Uruguai - isso naturalmente só se afigurava importante aos simples, aos rústicos da Campanha meridional do Brasil, na hora da luta armada (CÉSAR, 1978, p. 44).

Enquanto no concerto das nações modernas o território assumia, jurídica e politicamente, uma dimensão estratégica a remeter à centralidade do poder, a formação das nações e o bailado das fronteiras eram decididos por autoridades de um outro mundo, indiferente ao amálgama da gauchidade. Conforme Golin, a definição das fronteiras, combinada com "a conquista militar, a expansão demográfica e o recorrente uti possidetis, [...] significou uma opção imaginária, arbitrária, pesada na balança limitativamente possível da geopolítica” (GOLIN, 2002, p. 13). Com relação ao uti possidetis, cabe observar que essa expressão latina, cuja tradução poderia ser "possuis agora", é empregada no jargão jurídico para exprimir que se deve manter a coisa no estado em que se acha, ou na situação em que se encontra. No tocante à realidade platina, esse "foi sempre o recurso jurídico-político mediador de incorporação de territórios na construção dos espaços colonial e nacional" (GOLIN, 2002, p. 50), pois ele abrange o "princípio que incorpora as ações concretas da história na ocupação real dos territórios, criando direitos" (GOLIN, 2002, p. 50). As fronteiras pampianas conformam, portanto, o produto de um processo histórico de conquista e ocupação, não respeitando uma doutrina embasada na fronteira natural e no direito que a ela assistiria. No entorno platino, as diferenças entre limites e fronteiras, talvez de forma mais acentuada que em outros contextos, adquirem importância fundamental, visto que os primeiros foram:

[...] estabelecidos no papel, de forma convencional e imprecisa, através de bulas papais, tratados e acordos, contradança diplomática em que Portugal e Espanha procuravam acomodar seus interesses coloniais. Existe, porém, acentuada diferença entre 
limite, um fato jurídico, e fronteira, um fato político. O Rio Grande do Sul é um exemplo vivo dessa distinção. No final de contas, os nossos limites, traçados no papel, tiveram de ceder lugar às nossas fronteiras, estabelecidas pelos primeiros povoadores com respaldo das armas luso-brasileiras, a cujos interesses políticos elas serviam (REVERBEL, 1998, p. 68).

É possível então depreender que, ao contrário dos povos europeus, que sustentavam seu direito de autodeterminação em elementos secularmente delineadores da chamada "consciência nacional", entre nós, a delimitação do espaço deu-se em função dos interesses de uma elite ligada ao Estado, originária dos países ibéricos. Ao guerrear pelas fronteiras geopolíticas, os agentes estatais não visavam à defesa das margens de um sistema simbólico de pertencimento, mas, isto sim, à sua produção. As lutas marcadas pelo espaço físico e o esforço em definir os arbitrários limites das nações incipientes demonstraram a necessidade de se estabelecerem marcas culturais a designar o que faz e o que não faz parte da nação. Neste sentido, a literatura, como representação do nacional, conformou um dos tópicos mais convenientes para o reforço das tradições inventadas. Nesse interregno, expressões já consolidadas na linguagem corrente foram revisitadas e revestidas de novas significações, como ocorreu com os termos "gaúcho" e "castelhano".

\section{O GAÚCHO-HOMEM E O GAÚCHO-MITO}

O pampa é caracterizado, no plano cultural, pela unidade simbólica do "gaúcho". Palavra de origem controvertida, "gaúcho" designava "caçador de gado selvagem, contrabandista, teatino, andejo, coureador, desregrado, gaudério, changador; remanescentes de tribos guerreiras amestiçados com portugueses e espanhóis" (BOSSLE, 2003, p. 265). De um lado e de outro da fronteira física, o gaúcho não se encaixava nem na sociedade do europeu, nem na do índio. Sobrevivia "da caça e da venda de gado alheio ou selvagem, além de exercer o contrabando" (BEIRED, 1996, p. 18). Foi somente na segunda metade do século XIX, em meio às guerras pela independência, e quando estava à beira da extinção, que o gaúcho foi revalorizado em função de seu aproveitamento nas frentes de batalha (BEIRED, 1996, p. 18). A palavra revestiu-se, então, de "conteúdo nitidamente elogioso, de homem digno, bravo e destemido" (BOSSLE, 2003, p. 265). Do "gaúcho" restaram conhecidas "sua coragem e valentia; o amor à liberdade e o apego à terra; o espírito cavalheiresco, nobre e hospitaleiro; a gentileza para com as mulheres; o amor arraigado e constante às tradições" (BOSSLE, 2003, p. 265). 
É possível depreender que, à margem dos fatores históricos que concorrem para a depreciação e posterior mitificação do "gaúcho", há um cunho ideológico latente a nortear a ressignificação do vocábulo. o gaúcho, a designar o homem que habitava a campanha em tempos de fronteira aberta, campo aberto e gado solto, sobrevivia, como é sabido, de trabalhos "especiais", quase sempre ilícitos ${ }^{7}$. É evidente que as lidas corriqueiras do trabalho campeiro eram desempenhadas pelo negro, como escravo das grandes propriedades. Meyer, a esse respeito, observa que o fazendeiro comprava "os quinze ou vinte anos que podia dar-lhe o trabalho de um negro escravo por quantia correspondente à quadragésima parte do total empenhado em pagamento de um peão, no mesmo período" (MEYER, 1960, p. 25). A leitura sociológica do gaúcho/gaudério remete, pois, à depreciação decorrente das fraquezas políticas do entorno pampiano. Para os fazendeiros, o gaúcho era o ladrão ou o contrabandista a lhe molestar ou a lhe prestar serviços. Para as autoridades, ele serviu de lanceiro, miliciano, isca para o inimigo, conveniente, mas pouco confiável em face do eminente perigo da deserção.

Esses homens sem lei nem rei, que "moravam na sua camisa, debaixo do seu chapéu" [...] foram aproveitados muita vez nas arreadas e na guerra como campeiros ou bombeiros, mas o seu entendimento com as tropas regulares de espanhóis ou portugueses era um ajuste condicionado às obrigações momentâneas de serviço, combinadas entre as partes, e representava uma espécie de parêntese na sua vida habitual de gaudérios (MEYER, 1960, p. 19).

De qualquer sorte, os trabalhos do gaúcho teatino ${ }^{8}$ por esses campos garantiu, também, vantajosos rendimentos para ambas as nações ibéricas, visto que o entorno pampiano foi marcado tanto pela disputa armada de território quanto pelo contrabando. Léa Masina chega a declarar que "não existem fronteiras sem contrabando" (MASINA, 1995, p. 165). É pacífico o entendimento de que o contrabando, prática tão arraigada na cultura platina, a tal ponto de ter constituído um dos pilares da economia local já desde antes da formação do Vice-Reinado do Rio da Prata, em 1776, foi elemento propulsor do desenvolvimento regional, favoreceu a independência política das colônias e desempenhou relevante papel em meio às lutas pela demarcação de território.

7 A propósito, Augusto Meyer pondera que, antecedendo o vocábulo "gaúcho", aparecia nos documentos de uma e outra banda a palavra "gaudério", aplicada a "aventureiros paulistas que desertavam das tropas regulares, identificando-se com a vida rude dos coureadores e ladrões de gado" (MEYER, 1960, p. 19). Nesses termos, o gaudério teria ficado conhecido como aquele que tem por costume vender o que não é seu.

8 Emprega-se o termo em sua acepção regional de "cavalo ou boi e, por extensão, a coisa que, não se sabe a quem pertence; forasteiro, de outra terra” (FERREIRA, 1972, p. 1161). 
Masina observa que, no imaginário da população fronteiriça, o contrabando não constituía uma prática social indesejada (MASINA, 1995, p. 167), o que, portanto, eximia-o da condição de "crime". Conforme César:

Crime? Mas o contrabando, ali, não se enquadrava sequer na categoria de contravenção, que é um crime liliputiano. Passava-se até com os espanhóis, e seus descendentes platinos, que contrabandeavam também, escancaradamente, naquela zona, um fato curioso: seus rivais e vizinhos daquela praça de guerra muitas vezes os auxiliavam a enviar para outros "clientes", fora do Prata, suas mercadorias maculadas pela transgressão da lei. Isso ocorria, quase sempre, quando as relações entre a Colônia e Buenos Aires se turbavam, por motivo de guerra ou de intransigência ocasional dos agentes do fisco (CÉSAR, 1978, p. 43).

Nesses termos, depreende-se que o contrabando, não raras vezes, era instrumento de integração entre os habitantes do pampa, unindo-os, uns aos outros, em prol de burlar as regras impostas por um rei, português ou espanhol, visando ao lucro. O habitante desse campo aberto não poderia considerar crime $o$ ato de transportar, daqui para ali, as coisas que adquiria ou apresava. Porém, ainda na trilha de César, cabe lembrar que, lado a lado com o contrabando pessoal e o oficioso, convivia o contrabando de guerra (CÉSAR, 1978, p. 43), a institucionalizar a subtração. Também Reverbel tece seu comentário sobre a questão:

Era o roubo, praticamente, institucionalizado nas duas bandas, inclusive fazendo parte das guerras em que ambas se engajavam. Roubando-lhes os gados, bovinos e cavalares, os portugueses enfraqueciam seus inimigos da outra banda, econômica e militarmente. Da mesma forma procediam os espanhóis. [...] Acobertados por conveniências de Estado, esses aproveitadores ostentavam certa dignidade cívica, considerando-se merecedores do reconhecimento da pátria (REVERBEL, 1998, p. 80).

Apesar da pilhagem e do contrabando conformarem práticas arraigadas tanto de um quanto de outro lado da fronteira geopolítica, foi o Outro que passou a ser responsabilizado pela degradação dos bons costumes e das práticas sociais. Em processo inverso ao que teve lugar ante o termo "gaúcho" (a conformar um nós, desmarginalizado), o vocábulo "castelhano" foi acometido de uma anemia significativa para atender à ideologia nacionalizante que reclamava a caricaturização e depreciação do Outro. Assim, o Rio Grande do Sul apropriou-se do termo "gaúcho" para designar seu gentílico, esquecendo propositadamente que o "castelhano" era, tão-somente, o gaúcho "do lado de lá". Ao "castelhano", porém, vocábulo que originalmente 
designava a língua e a pessoa originária da região de Castela, em Espanha, restou o desígnio, de forma jocosa ou mesmo ofensiva, do desregrado, do invasor de terras, do responsável pelo roubo, pela pilhagem, pelo desrespeito às tradições, às mulheres, às famílias e às propriedades.

A evidente acepção ideológica a nortear as invenções das tradições do "gaúcho" sul-rio-grandense em face do outro "castelhano" tem na noção de fronteira a sua causa e sua consequência. Ao apresentar-se una e indivisível, livre de obstáculos naturais, a fronteira do Rio Grande do Sul com os Estados do Prata, especialmente com o Uruguai, era um convite ao diálogo e ao intercâmbio. Objeto de zelo e receio pelo poder central brasileiro, o Rio Grande do Sul foi alvo de todo um aparato ideológico a primar pelo controle e vinculação ao "caráter nacional". Assim, a construção da "brasilidade" requereu a definição de fronteiras simbólicas e o fortalecimento dessas pela modulação de um conjunto de significantes emblemáticos.

A produção literária no Rio Grande do Sul desenvolveu-se sob o signo da fronteira. Em seus primórdios, o personagem ficcional mais recorrente foi o gaúcho tal como o concebiam as vertentes literárias argentina ou uruguaia. A sucessão de guerras, porém, e a necessidade de se "abrasileirar" o Rio Grande do Sul foram, paulatinamente, inserindo-se no plano das letras e forjando uma narrativa mais afeita aos novos escopos ideológicos. $\mathrm{O}$ próprio modelo de "gaúcho", tal como apresentado na literatura, na música e nas artes em geral, foi sofrendo modificações e diferentes abordagens. Com efeito, a crítica tem demonstrado que a invenção do "gaúcho literário" deu-se pela geração dos filhos do levante farroupilha. A reivindicação de um direito à particularidade e à diferença e o fortalecimento da autoestima das elites incipientes estiveram na pauta dos grupos que se foram formando com a intenção de organizar (e inventar) a cultura no Rio Grande do Sul. A Sociedade Parthenon Literário ${ }^{9}$ que deu consistência à prática regular da literatura no Rio Grande do Sul, divulgou a imagem do "centauro dos pampas", do "monarca das coxilhas", nas instâncias de 1860. Chamou a atenção que, em meio às tendências do Romantismo e de seus ideais anticlássicos, haja-se instaurado por esses pagos uma instituição denominada "Parthenon", a reinventar um gaúcho com ares gregos por meio da alcunha do "centauro". o gaúcho mitologizado exerceu, pois, no plano regional, o papel que ao indígena foi reservado no âmbito do Romantismo nacional (AREND, 1995, p. 44).

Através da identificação com a figura mítica do gaúcho, universalizou-se a autoimagem da classe dominante que se projetou por todas

9 Conferir, acerca do Parthenon Literário, BAUMGARTEN (1997), DILLEMBURG (1987), ESTIMA (2009), MOREIRA (2002) e PÓVOAS (2009). 
as demais classes sociais, ansiosas de compartilhar glórias. Frente a um contexto histórico em que os espoliados não têm outro "luxo" ademais das histórias de valentia, reiteraram-se os esquemas narrativos como modelos de resistência, enquanto se teciam os subterfúgios para ocultar o pária do pampa, expulso da terra em função do cercamento dos campos ${ }^{10}$. Há que se ressaltar que o Parthenon era uma instituição engajada politicamente, tendo orientado o pensamento de muitos líderes da época, especialmente os promotores das ideias positivistas. As questões literárias, nesse contexto, andaram lado a lado com a política. O comprometimento ideológico da produção literária escrita no Rio Grande do Sul, desde o Parthenon, abarcando a geração de escritores da República Velha, terminou por formar um gaúcho literário distanciado do gaucho platino. Esse afastamento não foi, entretanto, fortuito: é possível considerar, com César, que "a idade de ouro da gauchesca, na prosa, ocupou os três primeiros decênios do século XX" (CÉSAR, 1994, p. 39), coincidindo com os roupantes nacionalistas a acompanhar a I Guerra Mundial e seus desfechos. O historiador observa que, já em 1898, tinha sido fundado, no Rio Grande, o Grêmio Gaúcho, iniciativa de Cezimbra Jacques, oficial reformado do Exército, com a finalidade de "resgatar" as tradições desses pagos. Porém:

[...] o simpático Major não admitia (e sirva o fato para documentar seu nacionalismo) qualquer aproximação do gaúcho rio-grandense - a personagem de ficção ou o tipo real - com o gaúcho platino, isto é, conforme ele mesmo diz, com "o borracho que vive a retoçar [sic] as polícias locais e a provocar desordens em a polpería e cometer crimes como se o vê pintado em Martín Fierro e Juan Moreira ${ }^{11}$ " (CÉSAR, 1994, p. 42) [grifos do autor].

Esse paradoxo só veio a ser reforçado com o advento das novas tendências estéticas e com a consciência autonômica cultural promovida pelo Movimento Modernista. Ademais, com a Revolução de 1930 e o golpe do Estado Novo, em 1937, o gaúcho mitificado passou a exercer um papel político mais evidente. Segundo Masina:

A polissemia do mito do gaúcho é flagrante: de um lado, criava-se, no Brasil, um modelo regional idealizado, fruto de uma terra de homens fortes, leais e íntegros, capazes de conduzir os destinos da

10 A exportação de couros pelo Rio da Prata terminou por acarretar a extinção do gado cimarrón, de modo que a tendência da coleta teve de se adaptar à criação. Da mesma forma, no fim do período colonial, expandiu-se a produção agrícola, especialmente a do trigo, promovendo a gradual valorização dos campos e a preocupação com a privatização das terras (REICHEL, 1998).

11 César, aqui, cita JACQUES (1912, p. 52). 
pátria. O gaúcho seria, pois, o oposto do Jeca Tatu, celebrizado por Monteiro Lobato nos alvores do século. Por outro lado, a divulgação da imagem do "centauro dos pampas" contribuía para fortificar a autoestima de um Estado espoliado pelo governo federal, cuja classe média, representada pela força militar, assegurara a vitória populista de Vargas (MASINA, 2002, p. 94).

Por uma dessas ironias da história, foi Getúlio Vargas quem acabou por "abrasileirar" o Rio Grande do Sul. Em nome de uma pretensa unidade, foram proibidos o hino e a bandeira sul-rio-grandense, bem como as demais manifestações de conotação regionalista. Esse quadro de opressão perdurou até 1945. O fim da ditadura coincidiu com o desfecho da II Guerra e fez emergir novas tendências no cenário sul-rio-grandense. Resgatando as tradições soterradas pela Era Vargas, ao mesmo tempo em que se opunham aos padrões culturais estadunidenses disseminados com a hegemonia do pós-guerra, um grupo de jovens estudantes liderados por Paixão Côrtes criou um Departamento de Tradições Gaúchas no Colégio Júlio de Castilhos, em Porto Alegre. Barbosa Lessa integrou-se ao movimento ansioso por fundar um "Clube de Tradições Gaúchas". Data de 24 de abril de 1948 a ata da fundação oficial do "35" Centro de Tradições Gaúchas, com o amparo do "Grupo dos Oito", ${ }^{12}$ da Patrulha do Quero-Quero e da maçonaria gaúcha ${ }^{13}$. A escolha do nome foi uma homenagem ao ano de 1835, quando eclodiu a Revolução Farroupilha.

Depois do "35", disseminaram-se os CTGs Rio Grande do Sul afora. Não obstante, há que se ressaltar que esse "regaste" de tradições tampouco primou pela reprodução do gaúcho sociológico, originário. A vestimenta, os cantos e os bailes vinham, também, imbuídos de invenções nacionalistas e imperialistas. Fagundes observa:

$\mathrm{Na}$ esteira mercantilista da Guerra do Paraguai veio [...] a gaita, que destronou a viola no reino dos bailes. E ao som das "duas conversas" as velhas danças do ciclo dos fandangos, sapateadas e completas (cada um com canto, música e coreografia) foram substituídas por "maneiras de dançar" impostas pelos novos ritmos trazidos no bojo dos foles: valsa, mazurca, polca, havaneira, chotes... E veio também a bombacha, de origem turca, que os comerciantes

12 Recebendo convite para montar uma guarda de gaúchos pilchados em honra ao herói farrapo, David Canabarro, que seria transladado de Santana do Livramento para Porto Alegre, Paixão Cortes, reuniu um piquete de oito gaúchos bem pilchados e, no dia 5 de setembro de 1947, prestaram a homenagem a Canabarro. Esse piquete é hoje conhecido como o Grupo dos Oito, ou Piquete da Tradição. Conferir: 35CTG. Histórico. Disponível em: < http://www.paginadogaucho.com. br/ctg/ctg35.htm >. Acesso em: 21 jun. 2015.

13 35CTG. Histórico. Disponível em: <http://www.paginadogaucho.com.br/ctg/ctg35. htm >. Acesso em: 21 jun. 2015. 
ingleses despejavam aos fardos no porto de Montevidéu, como sobra de guerra - restos do fardamento de seus exércitos colonialistas e imperialistas e mercantilistas (FAGUNDES, 1992, p. 95).

Contudo, a emergência da memória e a ascensão de uma consciência integradora (e agregadora) fizeram com que as práticas gauchescas pudessem ser entendidas como "formas de resistência e diálogo com as tendências homogeneizadoras bombardeadas pela televisão e pela mídia" (MASINA, 2002, p. 97). Apesar de a forte identidade regional do Rio Grande do Sul ter sido sempre "um empecilho para o reconhecimento e valorização da cultura gaúcha nos centros hegemônicos do país" (MASINA, 2002, p. 97), há uma tendência a apontar para uma mudança de paradigma e uma consequente legitimação das práticas artísticas sul-rio-grandenses. Da mesma forma, tem-se reconhecido os influxos platinos como tópico diferencial na confluência da cultura pampiana do Rio Grande do Sul.

\section{NOVOS ENFOQUES PARA OS INFLUXOS PLATINOS}

Paira a perspectiva de que o literário, na América Latina, tem referenciado a história local. Contudo, a preocupação em desmistificar o passado colonial tem levado em conta os processos simultâneos no que toca à formação do que restou referido como o "debate do Novo Mundo". A pesquisadora chilena Ana Pizarro observa que "la emancipación del discurso literario antecede en nuestro continente a la emancipación política" (PIZARRO, 1994, p. 23). Com efeito, mesmo em meio à hegemonia estrangeira, sobretudo no aspecto do capital, pensadores locais empenharam-se em expor suas ideias. Fossem ensaios políticos ou culturais, fossem comentários sobre literatura e arte, a questão é que as narrativas, às vezes "depoimentos" mesclados com biografias e memórias, compuseram um mosaico de grande importância não apenas para a consolidação de um discurso emancipado, mas também para uma visão política autônoma. Basta recordar a relevância da literatura popular no meio platino, especialmente no período da modernização, em que:

Se produce una desacralización del libro que servía a las élites ilustradas. El modo de producción industrial provoca un estímulo en las ventas y el comercio del folletín es una realidad. Los 150.00 ejemplares del folleto Carta Gaucha son un ejemplo. El deseo de lectura crece con la alfabetización y se satisface con los impresos de menor costo. El desarrollo del mercado popular del libro sigue una marcha que no tiene en cuenta las ediciones de alto costo únicamente para los grupos ilustrados y de élite. Es otro modo de comunicación y de adquisición de conocimientos y de disfrute de los grupos populares. El público compraba folletos con poesía popular, 
crónicas y relatos de variados acontecimientos de la vida diaria, leyendas gauchas en prosa y en verso, e infinidad de otros temas, en quioscos librerías, almacenes y a los vendedores ambulantes. Los editores contrataban los escritores y poetas para los futuros libros y folletos, cuyos títulos anunciaban en largas listas en las contratapas de los mismos. Folletos y libros en octavo, artesanales, para pobres (GUIDO, 1994, p. 396).

Essa formação de uma literatura à margem da ilustrada contribuiu para a propagação de causas sociais e libertárias. E os estudos literários, especialmente se considerados em seus vinculados com as noções de região cultural, fronteiras e identidades fronteiriças, não puderam se furtar de colher nos fatos históricos algumas relevantes noções teóricas. A temática do federalismo e as ânsias separatistas, por exemplo, são peças fundamentais para a compreensão das relações de pertencimento que particularizam as fronteiras culturais entre os países do Cone Sul, conformando um interessante projeto político por trás do plano simbólico (PICCOLO, 1998, p. 273-284). Os reflexos do quadro político platino no contexto sul-rio-grandense são notáveis: as sucessivas investidas brasileiras contra o Uruguai o ilustram. Certamente, a produção literária escrita no Rio Grande do Sul consolidou-se impregnada dos marcos históricos e políticos.

Não obstante, apesar das intrincadas relações entre os habitantes do entorno pampiano (ou exatamente por isso mesmo), a questão do nacional promoveu, no sistema literário brasileiro, a exclusão de obras marcadas pelo influxo platino. Paradoxalmente, a produção literária canônica e sua respectiva crítica estavam imbuídas do ideário nacional e nacionalista alemão e francês (OLIVEIRA, 2004, p. 54). A crítica que interpretou o regionalismo gaúcho como simples filiado à vertente romântica não considerou a questão em sua complexidade. Se "o regionalismo é um conjunto de retalhos que arma o todo nacional" (COUTINHO, 1997, p. 237), resta a dúvida se a produção literária escrita no Rio Grande do Sul pode ser resumida a esse papel. Embora também seja certo afirmar, tal como o faz Chiappini, que:

Na verdade, como manifestação do ressentimento de uma parcela das elites regionais, o regionalismo não se opõe ao nacionalismo; ao contrário, compõe com ele, da mesma forma que, mesmo perdendo a hegemonia, os fazendeiros do Nordeste ou do Rio Grande do Sul, apesar dos conflitos, em última instância compõe politicamente com as elites que detêm o poder no Centro do país, como forma de defesa e reforço da dominação que eles exercem na sua própria região (CHIAPPINI, 1994, p. 672). 
Nem praga antinacional, nem herdeira de Alencar, o fato é que a literatura gaúcha se viu influenciada pelo fato de compor o "único território brasileiro que o colonialismo lusitano conquistou mediante guerras contra outra potência colonial" (FREITAS, 1987, p. 10-11). A proximidade e os contatos do Rio Grande do Sul com o Rio da Prata foram, indubitavelmente, refletidos na sua produção escrita. No entanto, o abafar das vozes platinas e a negação dos influxos literários confluíam na tendência da "eliminação do que não é nativo" (SCHWARZ, 2001, p. 113), delineando o que Schwarz designou "nacional por subtração", sem tomar em conta o embuste que se promovia. Há que se considerar que a literatura sul-rio-grandense, apesar de orientada por princípios ideológicos de rechaço ao Prata, recebeu dele várias influências, estabelecendo um interessante diálogo com esse Outro.

$\mathrm{Na}$ afirmação da gauchidade brasileira, a influência platina fez-se sentir mesmo quando o objetivo primordial era negá-la, assemelhando-se a um vulto perturbador, com ares antinacionais, ainda que reiterasse, antes de tudo, um fenômeno regional. Não obstante, o conceito de região, frente à teoria literária , contemplou, tradicionalmente, somente duas situações: a que considera o lugar da enunciação literária (o lugar a partir de onde se escreve) e a que se ocupa do lugar como referência do texto (o lugar como tema sobre o qual se escreve). Só mais recentemente se deram a conhecer perspectivas como a de Ricardo Kaliman, que analisa o regional como o espaço pelo qual circula a literatura, ou seja, a comunidade que, por uma ou outra razão, acolhe o texto. Seguindo a esteira de Kaliman, em uma região definida pela prática de certos tipos de relatos orais, no curso da socialização, os agentes podem ter seus papéis alterados, passando, por exemplo, do rol de ouvintes ao de narradores (KALIMAN, 1994, p. 3-4). Ademais, o estudioso argentino fez notar que, nessa região, poderia haver agentes que, mesmo socializados em comunidades diferentes, viessem a estabelecer, de alguma maneira, relações de contato. Essas últimas, de acordo com Cioranescu, "suponen la presencia de una especie de ecuación, cuyos términos de comparación tienen por condición la de pertenecer a dos [o más] literaturas nacionales" (CIORANESCU, 1964, p. 74), e podem se dar através de viagens, de leituras, por meio de intermediários (como professores de língua estrangeira), trabalhos de pesquisa ou de traduções, ou ainda pela imitação e pela influência.

No caso do pampa, cenário por excelência da literatura gauchesca, e do Rio Grande do Sul como locus de enunciação literária, deve-se agregar, então, outra perspectiva, desvinculada da noção de fronteira política, para contemplar as relações de contato com Prata, partindo de uma noção de região não como espaço em si, mas como uma função sobre o espaço. Esse pampa de relatos vários e de temas comuns, resgatado pela "geração dos homens tristes de saudade" (FAORO, 1998, p. 23), foi, ainda, uma forma de 
lidar com a morte, real ou simbólica, da fronteira, um jeito de "renascer pela memória" e de reunir os pedaços de identidades partidas pela "manipulación ideológica de la homogeneidad, el de las naciones-estado" (KALIMAN, 1994, p. 2). Cabe destacar que, no entorno pampiano, o processo de travessia de fronteiras não foi determinado pela crítica, mas pela transmissão oral, a partir das cidades da fronteira e, particularmente, por sua circulação nas estâncias e pequenos lugarejos interioranos.

Com efeito, o influxo platino - visto com maus olhos pela crítica tradicional - conferiu peculiaridade aos textos da literatura fronteiriça, possibilitando uma visão múltipla das culturas latino-americanas meridionais em diálogo. É possível vislumbrar a influência de José Hernández não apenas sobre Simões Lopes Neto, mas sobre uma vasta gama de escritores gaúchos, como Alcides Maya, Aureliano Figueiredo Pinto, Aparício Silva Rillo, Darcy Azambuja e Luis Carlos Barbosa Lessa. Também Cyro Martins, em Para início de conversa, admitiu ter influências de José Hernández e mencionou que ouviu Martín Fierro sendo declamado na campanha. De fato, a trajetória e os conselhos de Martín Fierro fazem parte, também, do imaginário do povo do Rio Grande do Sul. Conforme Pesavento, isso não é de se estranhar: "existe sempre como que um mercado de de ideias e imagens, que viajam no tempo e no espaço, sendo a escrita sempre um palimpsesto, em que é possível ler, em um autor, a presença das ideias do outro, ainda mais quando são vivenciados, historicamente, problemas comuns" (PESAVENTO, 2004, p. 111).

Apesar disso, o influxo platino na literatura sul-rio-grandense foi negado sistematicamente pela crítica. Poucos foram os intelectuais cujas vozes se alçaram a contrariar a tendência lusófona dominante (MASINA, 1998, p. 116-125). E a mentalidade brasileira, engajada na construção da brasilidade, ao negar a complexidade dos fatores que confluíam junto à produção literária sul-rio-grandense, não soube apreciá-la na sua inteireza. Enquanto isso, no Prata, a propagação de obras de cunho político-ideológico levava a crer que os conflitos que definiam a relação da cultura com a ação social se propunham mais a combater inimigos internos. $O$ espaço da poesia era o espaço da reflexão política (MATTALíA, 1994, p. 253-258). Não obstante, há que se considerar, com Guido, que, também entre os platinos:

Las protestas y rebeliones se suceden debido a la forma como los gobiernos impulsan la modernización: la distribución de las tierras para los extranjeros desconociendo los derechos de los nativos, la mentalidad distinta de los inmigrantes frente a la criolla, la industrialización, el alambrado de los campos, entre tantas otras razones, provocan resentimientos en los locales, lo cual muchas veces degenera en bandolerismo y bandidismo. Los sectores marginados por la nueva mano de obra se convierten en xenófobos, pero inconscientemente van asimilando nuevas pautas traídas por los inmigrantes (GUIDO, 1994, p. 388). 
O sentimento anti-lusitano, de igual forma, foi uma constante entre os platinos, especialmente os uruguaios, em função das sucessivas disputas por territórios e das décadas de intervenção política e econômica. Além do mais, fazia parte do projeto de autoafirmação política "acomodar" as diversidades sob o teto do Estado-nação ao mesmo tempo em que se definiam fronteiras culturais a demarcar o Outro. Foi somente a partir da segunda metade do século XX que se passou a perceber um esforço sistemático de pesquisar e coletar dados que se propusessem a rever textos canônicos, fundadores ou importantes por representarem as transformações sociais que afetaram o cotidiano nesses pagos. Foram relidos e revistos os pilares da literatura pampiana, seguindo o embalo de uma tendência latino-americana:

De una manera o de otra, son casi dos centurias en las que escritores y pensadores latinoamericanos se han preocupado por la independencia intelectual y artística. Pero, repetimos, es a partir de los años 60 cuando se multiplican los estudios e instituciones que tratan de sentar las bases para una redefinición radical de la crítica literaria latinoamericana, sus premisas teóricas y su objeto, tales como AELSAL, ABRALIC, CELCIRP, el Instituto de Estudios Culturales Latinoamericanos de Dartmouth College, entre otros, así como las nuevas editoriales surgidas en Latinoamérica: Casa de las Américas, en La Habana, y Fundación Biblioteca Ayacucho, en Caracas, que promueven y difunden textos latinoamericanos (GUIDO, 1994, p. 403).

No Rio Grande do Sul, a partir dos anos 1950, intensificando-se nos 1970, passou-se a promover nas universidades locais o desejo de aprofundar o conhecimento da literatura gaúcha, mapeando suas origens culturais e diagnosticando suas possibilidades. Revistas, textos críticos e obras literárias trataram das diferentes perspectivas da cultura gaúcha. É importante destacar a força política desse questionamento, pois se vivia uma ditadura que mirava com zelo e receio as culturas fronteiriças. Muitas regiões gaúchas estavam inseridas no rol das "áreas de segurança nacional". O Rio Grande do Sul arcou com o ônus de ver suas principais cidades ficarem sem poder eleger nem sequer o prefeito ${ }^{14}$, ao passo que em outros Estados da

14 Conforme dados fornecidos pela FAMURS (Federação da Associação de Municípios do Rio Grande do Sul), não havia eleições diretas nas consideradas “áreas de segurança nacional”, a incluir capitais, municípios de fronteira, estâncias hidrominerais e pólos de petróleo. Em função da localização privilegiada do Rio Grande do Sul e porque vários de seus municípios estavam elencados nas prerrogativas supra, a restrição a eleições diretas para o Executivo Municipal atingiu várias cidades gaúchas. A título de exemplo, além de Porto Alegre, Canoas, Tramandaí, Torres, Osório, Quaraí, Uruguaiana, Iraí, Rio Grande, Porto Xavier, Santana do Livramento, São Borja, Itaquí, Horizontina, Tenente Portela, Jaguarão, Bagé, Dom Pedrito, Santa Vitória do Palmar e São José do Norte, entre outras não mencionadas aqui. 
Federação só à capital foi imposta essa reserva. E cabe, ainda, destacar que três dos cinco generais-presidentes desse período ditatorial eram gaúchos ${ }^{15}$. Conforme Bosi, "se a nossa história política nos ajuda a estabelecer o divisor de águas, este poderá passar pela fase mais negra da ditadura militar, entre 1964 e 1974, com toda a sua carga de opressão, exílio e censura" (BOSI, 1994, p. 435). Porém, enquanto no plano cultural parecia haver um "esvaziamento" em função dos vários setores amordaçados, do ponto de vista econômico, ingressava-se nos "anos do milagre" de 10\% de taxa de crescimento anual (SKIDMORE, 1994, p. 271). Embora às custas de uma inimaginável dívida externa, o país modernizou-se agressivamente. A implantação da EMBRATEL, em 1969, marcou a maturidade da televisão como veículo de comunicação e acabou por domesticar o Brasil. Em uma sociedade de baixa escolaridade média e índices altos de analfabetismo, sem tradição de leitura e carente de grupos de interesses politicamente eficazes (SKIDMORE, 1994, p. 271), a televisão representou, mais do que diversão e notícias, a veiculação dos interesses do poder ${ }^{16}$. Ocupando a lacuna deixada pelos afetos esmaecidos e pelas tradições em declínio, telenovelas captavam a atenção das famílias em meio à euforia modernizante. O papel da televisão, a "docilidade" de um povo sem instrução, uma sociedade civil incapaz de se articular e a habilidade dos militares brasileiros em promover negociatas e resgatar os sentimentos nacionalistas atenuaram a repressão: em 20 anos de ditadura, o número de mortos e "desaparecidos" foi de, aproximadamente, 1.000 pessoas em um país com 90 milhões. Já na Argentina, de arraigadas tradições culturais, foram entre 15.000 e 25.000 mortos e "desaparecidos" em dez anos (SKIDMORE, 1994, p. 273). E há que se ressaltar que a Argentina não chegava a somar o equivalente à sétima parte da população brasileira de então. No Uruguai, quase uma centena de pessoas foi morta dentro dos presídios e outros 200 uruguaios desapareceram, muitos deles durante o exílio na Argentina, no Chile, Paraguai ou Brasil ${ }^{17}$. Nesse país, os presos políticos contabilizaram 35 para cada 10.000 habitantes.

15 Sucedendo a Castello Branco, o marechal Arthur da Costa e Silva, natural de Taquari, assumiu o poder em 15 de março de 1967 e governou até 31 de agosto de 1969, quando foi afastado do poder por motivo de saúde. Em 30 de outubro de 1969, tomou posse Emílio Garrastazu Médici, procedente de Bagé. Seu governo ficou conhecido como "os anos negros da ditadura" em função de o movimento estudantil, sindical e as oposições terem sido duramente silenciados pela repressão policial. Gaúcho de Bento Gonçalves, o general Ernesto Geisel assumiu a Presidência em 15 de março de 1974 e governou até 15 de março de 1979 . Em seu governo, a dívida externa contraída para financiar as obras faraônicas atingiu US\$ 9,5 bilhões e, devido ao expressivo crescimento das oposições nas eleições parlamentares de 1974, promulgou-se a Lei Falcão, que impedia o debate político nos meios de comunicação. O ciclo militar fechou-se com Figueiredo.

16 E, portanto, a formação de novos padrões de identidade e alteridade, lembrando, com Deane: "the determination of what is "difference" or "otherness" might itself be a ruse of power" (DEANE, 1990, p. 357).

17 EL CLARÍn. Hallan archivos de la dictadura en Uruguay. 01 jul. 2006. Disponível em: <http://www.clarin.com/diario/2006/07/01/um/m-01226112.htm >. Acesso em: 18 jun. 2015. 
Até o momento em que eclodiram os golpes nos países vizinhos, as fronteiras representaram, ademais, a possibilidade de acesso às ideias. Ia-se a Montevideo comprar Dostoievski, discutia-se Trotsky em cafés de Buenos Aires e especulava-se sobre a política de Salvador Allende. No Chile, os militares tomaram La Moneda em 1973 , três meses depois do golpe no Uruguai. Na Argentina, a ditadura foi instaurada em 1976. Contrastando com a relativa calmaria entre nós, na Argentina, os montoneros conformavam "o maior e mais bem organizado movimento guerrilheiro da América Latina dos últimos 50 anos" (SKIDMORE, 1994, p. 273). No Uruguai, também os Tupamaros defendiam a luta armada e uma terceira força política emergia no contexto social: a Frente Amplio, congregando os descontentes entre blancos e colorados.

Somente com os novos ares provindos da abertura política e do restauro da democracia coube à crítica reavaliar o legado cultural gaúcho sob um novo viés: o da integração ${ }^{18}$. Entre os anos 1980 e 1990, os estudos de Literatura Comparada acentuaram a ruptura com o pensamento modernista stricto sensu (SCHMIDT, 2004). O estudo da literatura foi-se liberando do seu caráter mais formalista, e uma visão mais crítica de produção de cultura propôs-se a rever conceitos atrelados à identidade, em suas diversas facetas. Perspectivas feministas, clamores de minorias étnicas e religiosas e aspectos relacionados à autoafirmação de setores regionais foram se fortalecendo ante a perspectiva de inclusão de diversas igualdades e liberdades como garantias constitucionais protegidas por cláusula pétrea, no Artigo $5^{\circ}$ (SILVA, 1998, p. 214-215).

No seio da euforia democrática, as tendências autoritárias e normativas no interior das narrativas eram questionadas e rearticuladas. Assinalando novas possibilidades de sentido e novas estratégias de significação em face do mesmo amparo da Lei Máxima, abriu-se caminho para a uma reconfiguração de povo, nação e cultura. Esta última, como promotora que é do diálogo entre as diferenças e da "luta contra a uniformidade" (SANTOS, 2002, p. 47), passou a ser objeto de interessantes políticas públicas orientadas pelos tomadores de decisão em uma democracia incipiente, ainda receosa

18 Merece destaque, neste sentido, a criação do Mestrado em Integração Latino-Americana, na Universidade Federal de Santa Maria (UFSM), em 1997. Especial importância tem a criação da Universidade Federal da Integração Latino-Americana (UNILA), em 2010, pelo então Presidente da República Luís Inácio Lula da Silva, sediada em Foz do Iguaçu, em uma região estratégica: a Tríplice Fronteira Brasil-Paraguai-Argentina. A UNILA, por sua vez, institucionaliza sobremaneira o interesse pela produção de conhecimento acerca das fronteiras - tanto as territoriais quanto as epistemológicas - com a criação de dois cursos de pós-graduação strictu sensu: o Mestrado em Integração Contemporânea da América Latina, criado em 2014, e o Mestrado Interdisciplinar em Estudos Latino-Americanos, criado em 2013. 
do papel do Estado ${ }^{19}$. Entre as mudanças da nova Carta, estava o parágrafo único do Art. $4^{\circ}$ da Constituição, a estabelecer: "[a] República Federativa do Brasil buscará a integração econômica, política, social e cultural dos povos da América Latina, visando à formação de uma comunidade latino-americana de nações".

As várias iniciativas no sentido de aproximar as culturas brasileira sul-rio-grandense e platina ilustram a preocupação com a similitude que sempre existiu nas zonas de fronteira. Nesse viés, a abordagem da fronteira como valor universal aproxima-se da noção de frontería ${ }^{20}$. Assim, embora até este momento não se tenha tido muitos êxitos na esfera comercial, a inclusão do Mercosul na pauta do dia ao menos reavivou as velhas polêmicas culturais sobre as aproximações e os rechaços entre os brasileiros e seus vizinhos - e entre os gaúchos sul-rio-grandenses e seus correlatos platinos, de forma mais específica. Sob essa égide, houve alguns intentos no tocante à implementação do ensino de língua espanhola nas escolas e recuperou-se o emblema das cidades fronteiriças para simbolizar a integração, em detrimento da antiga imagem de ameaça à segurança nacional. Ilustrando essa utopia, o parque internacional, entre Santana do Livramento e Rivera, voltou a centrar atenções. Reavivou-se, enfim, o sentimento de que as fronteiras, se não são abertas, pelo menos são permeáveis.

\section{REFERÊNCIAS}

AREND, João Cláudio. O mito do gaúcho-herói e o imaginário social em Contos gauchescos e Lendas do sul. Dissertação (PPG - História - Mestrado) - UNISINOS, São Leopoldo, 1995.

BARRÁn, José Pedro. Apogeo y crisis del Uruguay pastoril y caudillesco (1839 - 1875). Montevidéu: Ediciones de la Banda Oriental, 1990.

BAUMGARTEN, Carlos Alexandre. A crítica literária no Rio Grande do Sul: do Romantismo ao Modernismo. Porto Alegre: EDIPUCRS; IEL, 1997.

19 Há que se recordar o desgaste que foi para o governo José Sarney a criação do Ministério da Cultura, depois extinto pela gestão de Fernando Collor. Visto mais como uma forma de escoar as verbas públicas, o financiamento da cultura só pôde se estruturar mediante a adoção de um padrão "misto", associando recursos públicos aos de origem empresarial. Nesses termos, concebeu-se a Lei Rouanet (Lei n. ${ }^{\circ}$ 8313/91), regulamentada pelo Decreto n. ${ }^{\circ}$ 1494/95. Em âmbito estadual, tem-se a Lei de Incentivo à Cultura (Lei n. ${ }^{\circ} 10.846 / 96$ ). A propósito, ver: DURAND, José Carlos. A cultura como objeto de política pública. São Paulo em perspectiva, v. 15, n. 2, 2001. Disponível em: <http:// www.scielo.br/pdf/spp/v15n2/8579.pdf>. Acesso em: 18 jun. 2015.

20 Antigo sinônimo espanhol para "fronteira", que referia a ação de criar novas frentes, abrindo novas trilhas. $\mathrm{O}$ atual emprego desse vocábulo exerce a função de traçar a oposição entre a visão tradicional de fronteira (com seu escopo de definir limites e forjar identidades e alteridades) e outra perspectiva mais afeita às tendências contemporâneas, de habilitação das memórias fragmentadas e de abertura de relações (VOLPE, [s/d], p. 71). 
BEIRED, José Luis Bendicho. Breve história da Argentina. São Paulo: Ática, 1996.

BHABHA, Homi K. O local da cultura. Belo Horizonte: UFMG, 1998.

BOSI, Alfredo. História concisa da literatura brasileira. 35. ed. São Paulo: Cultrix, 1994.

BOSSLE, João Batista Alves. Dicionário gaúcho brasileiro. Porto Alegre: Artes e Ofícios, 2003.

CAMPA, Román de la. Latinoamérica y sus nuevos cartógrafos. Revista Iberoamericana, v. 62, n. 176-177, p. 298-368, jul./dez. 1996.

CÉSAR, Guilhermino. O contrabando no sul do Brasil. Caxias do Sul: Universidade de Caxias do Sul; Porto Alegre: Escola Superior de Teologia São Lourenço de Brindes, 1978.

Editora da Universidade, 1994.

. Notícia do Rio Grande: literatura. Porto Alegre: Instituto Estadual do Livro /

CHIAPPINI, Lígia. Velha praga? Regionalismo literário brasileiro. In: PIZARRO, Ana (Org.). América Latina: palavra, literatura e cultura. Volume II. São Paulo: Memorial; Campinas: UNICAMP, 1994. p. 665-702.

CHIAPPINI, L; MARTINS, M. H.; PESAVENTO, S. J. (Orgs.). Pampa e cultura: de Fierro a Netto. Porto Alegre: UFRGS / Instituto Estadual do Livro, 2004.

CIORANESCU, Alejandro. Princípios de literatura comparada. Tenerife: Universidad de la Laguna, 1964.

COTTET, Serge. Penso onde não sou, sou onde não penso. In: MILLER, Gerard (Org.) Lacan. Tradução de Luiz Forbes. Rio de Janeiro: Jorge Zahar, 1989. p. 11-23.

COUTINHO, Afrânio. A literatura no Brasil. 4. ed. rev. atual. São Paulo: Global, 1997.

DEANE, Seamus. Imperialism/nationalism. In: LENTRICCHIA, F.; MCLAUGHLIN, T. (Eds.). Critical terms for literary study. 2. ed. Chicago: The University of Chicago Press, 1990. p. 354-368.

DIAS, Marcelo Henrique. O Rio Grande do Sul em face ao Prata. In: ALMEIDA. Jaime de (Org.). Tendências e contornos de um campo historiográfico. Brasília: ANPHLAC, 1998. p. 97-135.

DILLENBURG, Sérgio Roberto. A imprensa em Porto Alegre de 1845 a 1870. Porto Alegre: Sulina/ARI, 1987.

DURAND, José Carlos. A cultura como objeto de política pública. São Paulo em perspectiva, v. 15, n. 2, 2001. Disponível em: <http://www.scielo.br/pdf/spp/v15n2/8579.pdf>. Acesso em: 18 jun. 2015.

EL CLARÍn. Hallan archivos de la dictadura en Uruguay. 01 jul. 2006. Disponível em: <http:// www.clarin.com/diario/2006/07/01/um/m-01226112.htm >. Acesso em: 18 jul. 2015.

ESTIMA, Vinícius Marques. A história da literatura do Rio Grande do Sul, de Guilhermino Cesar: o inventário do período de formação da literatura sul-rio-grandense. Dissertação (Mestrado em História da Literatura) - Universidade Federal do Rio Grande, 2009.

FAGUNDES, Antônio Augusto. E o gaúcho, morreu? In: FISCHER, L. A; GONZAGA, S. (Orgs.). Nós, os gaúchos. Porto Alegre: UFRGS, 1992. p. 9-14.

FAORO, Raimundo. Introdução ao estudo de Simões Lopes Neto. In: TARGA, Luiz Roberto Pecoits (Org.). Breve inventário de temas do sul. Porto Alegre: UFRGS / Fundação de Economia e Estatística; Lajeado: UNIVATES, 1998. p. 13-19.

FERREIRA, Aurélio Buarque de Hollanda. Pequeno dicionário da língua portuguesa. 11. ed. São Paulo: Companhia Editora Nacional, 1972.

FRANCO, Sérgio da Costa. Panorama sócio-cultural da fronteira Brasil-Uruguai. Verso e reverso, São Leopoldo, n. 11, p. 29-42. jul./dez. 1992. 
FREITAS, Décio. A exploração das fronteiras do Sul. Leitura, São Paulo, v. 6, n. 66, p. 10-31, nov. 1987.

GOLIN, Tau. A fronteira. Porto Alegre: LP\&M, 2002.

GUIDO, Clara Rey de. La literatura popular rioplatense en el período de la modernización. In: PIZARRO, Ana (Org.). América Latina: palavra, literatura e cultura. Vol. II. São Paulo: Memorial; Campinas: UNICAMP, 1994. p. 385-404.

HALL, Stuart. A identidade cultural na pós-modernidade. Tradução de Tomás Tadeu da Silva e Guacira Lopes Louro. 7. ed. Rio de Janeiro: DP\&A Editora, 2003.

JACQUES, Cezimbra. Assuntos do Rio Grande do Sul. Porto Alegre: Of. Gráficas da Escola de Engenharia, 1912.

KALIMAN, Ricardo. Un marco (no "global") para el estudio de las regiones culturales. In: JILAR. Tucumán: Facultad de Filosofia y Letras; Instituto de Historia y Pensamiento Argentinos, 1994. p. 2-23.

LEENHARDT, Jacques. Fronteiras, fronteiras culturais e globalização. In: MARTINS, Maria Helena (Org.). Fronteiras culturais: Brasil - Uruguai - Argentina. São Paulo: Ateliê Editorial, 2002. p. 27-34.

MARTINS, José de Souza. Fronteira. São Paulo: Hucitec, 1997.

MASINA, Léa. O contrabando na confluência de culturas. In: CASTELLO, J. R. et al. (Org.) Práticas de integração nas fronteiras. Porto Alegre: UFRGS / Goethe / ICBA, 1995. p. 87-101.

. A gauchesca brasileira. In: MARTINS, Maria Helena (Org.). Fronteiras culturais: Brasil - Uruguai - Argentina. São Paulo: Ateliê Editorial, 2002. p. 93-106.

. Alcides Maya: um sátiro na terra do Currupira. Porto Alegre: Instituto Estadual do Livro; São Leopoldo: Unisinos, 1998.

MATTALÍA, Sonia. Ensayos de teoría de una visión americana. In: PIZARRO, Ana (Org.). América Latina: palavra, literatura e cultura. Vol. II. São Paulo: Memorial; Campinas: UNICAMP, 1994. p. 243-268.

MELO, José Luiz Bica de. Fronteiras abertas: o campo do poder no espaço fronteiriço Brasil-Uruguai no contexto da globalização. Tese (Programa de Pós-Graduação em Sociologia - Doutorado) - Universidade Federal do Rio Grande do Sul, Porto Alegre, 2000.

MEYER, Augusto. Prosa dos pagos. Rio de Janeiro: Livraria São José, 1960.

MOREIRA, Maria Eunice (Org.). Narradores do Parthenon Literário: primeiros textos. Porto Alegre: Instituto Estadual do Livro, 2002.

OLIVEIRA, Denise Vallerius de. Repensando as fronteiras: a tradução de identidades na obra de Jorge Luis Borges. Organon, Porto Alegre, v. 18, n. 37, p. 51-63, 2004.

PESAVENTO, Sandra Jatahy. Gaúcho: mito e história. Letras de hoje, Porto Alegre, n. 77, p. 55-63, set. 1989.

. História do Rio Grande do Sul. 9. ed. Porto Alegre: Mercado Aberto, 2002.

. Fronteiras e intertextualidade em o continente, de Érico Veríssimo. In: CHIAPPINI, L; MARTINS, M. H.; PESAVENTO, S. J. (Orgs.) Pampa e cultura: de Fierro a Netto. Porto Alegre: Editora da UFRGS / Instituto Estadual do Livro, 2004. p. 287-299.

PICCOLO, Helga Iracema Landgraf. o federalismo como projeto político no Rio Grande do Sul. In: TARGA, Luiz Roberto Pecoits (Org.). Breve inventário de temas do sul. Porto Alegre: UFRGS / Fundação de Economia e Estatística; Lajeado: UNIVATES, 1998. p. 273-284. 
PIZARRO, Ana (Org.). América Latina: palavra, literatura e cultura. São Paulo: Memorial; Campinas: UNICAMP, 1994. Três volumes.

La emancipación del discurso. In: PIZARRo, Ana (Org.). América Latina: palavra, literatura e cultura. Vol. II. São Paulo: Memorial; Campinas: UNICAMP, 1994. p. 59-97.

PÓvOAS, Mauro Nicola. Fontes primárias e dúvidas literárias: o caso Murmúrios do Guaíba. Iluminart, São Paulo, v. 1, n. 1, p. 69-76, 2009.

PRATT, Mary Louise. Arts of the Contact Zone. Profession, v. 91, p. 33-40, 1991. Disponível em: $<$ http://learning.writing101.net/wp-content/readings/pratt_arts_of_the_contact_zone.pdf $>$. Acesso em: 18 jun. 2015.

REICHEL, Heloísa Jochins. A valorização da propriedade da terra em uma sociedade em transformação. In: ALMEIDA, Jaime de (Org.). Tendências e contornos de um campo historiográfico. Brasília: ANPHLAC, 1998. p. 186-199.

REVERBEL, Carlos. o gaúcho. Porto Alegre: L\&PM, 1998.

ROMANO, Eduardo. Originalidad americana de la poesía gauchesca. In: PIZARRO, Ana (Org.). América Latina: palavra, literatura e cultura. Vol. II. São Paulo: Memorial; Campinas: UNICAMP, 1994. p. 127-159.

SANTIAGO, Silviano. Uma literatura nos trópicos. 2. ed. Rio de Janeiro: Rocco, 2000.

SANTOS, Boaventura de Souza. Linha de horizonte. In: e as ciências sociais. 2. ed. São Paulo: Cortez, 2002. p. 29-58. (Org.). A globalização

SCHMIDT, R. T. Porto Alegre: cultural center of Southern Brazil. In: VALDÉS, Mario J.; KADIR, Djelal (Ed.). Literary Cultures of Latin America: a comparative history. Vol. II. New York: Oxford University Press, 2004. p. 626-638.

SCHWARZ, Roberto. Nacional por subtração. In: SCHWARZ, Roberto. Cultura e política. São Paulo: Paz e Terra, 2001. p. 92-136.

SELIGMANN-SILVA, Márcio. O local da diferença. São Paulo: Editora 34, 2005.

SILVA, José Afonso da. Curso de Direito Constitucional positivo. 15. ed. rev. e atual. São Paulo: Malheiros, 1998.

SKIDMORE, Thomas. O Brasil visto de fora. Tradução de Susan Semler. Rio de Janeiro: Paz e Terra, 1994.

VOLPE, Miriam. Geografias del exílio: Mario Benedetti. Montevidéu: Ediciones La Gotera, [s/d].

Submetido em: 21/07/2014

Aceito em: 25/07/2014 